\title{
TRAÇADOS SINGULARES NA FORMAÇÃO DE PROFESSORES ${ }^{1}$
}

\author{
Dhemersson Warly Santos Costa ${ }^{2}$ \\ Yasmin De Souza Baia ${ }^{3}$ \\ Maria dos Remédios de Brito $^{4}$
}

\begin{abstract}
Resumo: A formação de professores tem percorrido os trilhos do pensamento dogmático, compromissado com o universal, o semelhante e a reproduçáo. Tal perspectiva não permite que as fissuras inventivas sejam postas como formas de criação. Nesse sentido, em que medida a formação de professores desafia a percorrer traçados singulares em que os encontros inventivos e acontecimentais sejam vetores de novos modos que percorram as práticas educativas e formativas? O presente ensaio pretende dialogar com a filosofia da diferença, buscando um percurso cartográfico a partir de uma experiência traçada no interior de uma sala de aula de um curso de formação de professores da Universidade Federal do Pará. Entende-se que é possível engendrar outros processos formativos na formação de professores em que sejam ouvidos os gestos singulares nas práticas educativas, a fim de abrir múltiplas formações para além dos pressupostos sedentários.
\end{abstract}

Palavras-chave: Formação de professores. Singularidades. Cartografia.

1 O ensaio é resultado dos desdobramentos do projeto de pesquisa "Filosofia da diferença e educação: conexões deleuzianas", sob coordenação da professora Dra. Maria dos Remédios de Brito, Universidade Federal do Pará.

2 Universidade Federal do Pará. Graduado em Ciências Biológicas-UFPA. Atualmente mestrando em Educação em Ciências pelo Instituto de Educação Matemática e Científica dhemersonsantos@hotmail.com.

3 Universidade Federal do Pará. Graduando em Licenciatura Integrada em Educação em Ciências, Matemáticas e Linguagem. yas_ufpa@hotmail.com.

4 Graduada em Filosofia pela Universidade Federal do Pará; Pós Doutora em Filosofia da Educação pela Universidade de Campinas-UNICAMP. Professora da Universidade Federal do Pará. Ligada aos Programas de Pós-Graduação em Educação em Ciências e Matemáticas PPGECM/UFPA e Artes/ICA, UFPA Email: mrdbrito@hotmail.com. 


\title{
SINGULARITIES TRAININGS IN TEACHER TRAINING
}

\begin{abstract}
The training of teachers has been traversed by dogmatic thought, committed to the universal, the similar and reproduction. Such a perspective does not allow inventive cracks to be cast as forms of creation. In this sense, to what extent does teacher training challenge the trajectory of singular ways in which inventive and eventful encounters are vectors of new ways that go through educational and formative practices? This essay intends to dialogue with the philosophy of difference, seeking a cartographic course from an experience traced inside a classroom of a teacher training course of the Federal University of Pará. It is understood that it is possible to generate other formative processes in the formation of teachers in which the singular gestures in the educational practices are heard, in order to open multiple formations beyond the sedentary presuppositions.
\end{abstract}

Keywords: Teacher training. Singularities. Cartography.

A formação de professores ${ }^{5}$, enveredada pelo projeto moderno de massificação da educação, busca forjar um professor universal a partir de "receitas" prontas e acabadas, prostrado para uma educação dogmática, cuja função é educar pela regra e não pela exceção (GALLO, 2016), uma verdadeira aliança com a finalidade, a objetividade e a hierarquia. Enclausurados nas armaduras da representação, os sujeitos participativos no processo formativo não comportam diferenças, singularidades, mas, antes de tudo, "uma forma, uma essência, que é atravessado por relações de verdade, unidade, objetividade, correção" (BRITO, 2015, p. 87).

Todavia, uma sala de aula não é um território fechado, embora as fronteiras sejam muito bem demarcadas por paredes, também não é um lugar de clausuras e dominação, mas um mapa aberto às intensidades, aos fluxos desejantes por onde transitam as diferenças. Com isto, indaga-se: em que medida a formação de professores desafia a percorrer traçados singulares em que os encontros inventivos e acontecimentais sejam vetores de novos modos que percorram as práticas educativas e formativas? Como seria pensar a formação de professores pelas linhas da singularidade? Que efeitos poderiam ser produzidos no curso de formação de professores em Educação em Ciências, Matemática e Linguagem da Universidade Federal do Pará? Como fissurar esse espaço formativo solidificado sob a ótica da uniformização?

5 A literatura sobre a formação de professores é vasta. Diversos autores (NOVOA, 2002; SCHÖN, 1992; ZEICHNER, 1993; GIL-PÉREZ; CARVALHO, 1993; GONÇALVES; GONÇALVES, 1998) denunciam a insuficiência dos cursos de licenciatura na formação de profissionais dotados de saberes científicos e pedagógicos com vistas a transformar toda a diversidade conceitual em efetivo aprendizado. Mesmo com todos os investimentos nos últimos, as avaliações institucionais nacionais e internacionais da educação básica revelam o cenário caótico da educação no Brasil. 
O presente ensaio experimenta cartografar ${ }^{6}$ singularidades que povoam o território de uma sala de aula de um curso de formação de professores, entendendo que a cartografia é movimento aberto ao incerto, às linhas intensivas, sabendo que existem múltiplas entradas em um mapa como a sala de aula, sem horizontes ou fronteiras, travessias na qual, professorandos e professores, são convidados a se aventurarem no interior de um panorama único e acontecimental. Nesse sentido, a escrita vem também como experimento neste solo incerto do espaço da formação.

\section{Travessia I: a educaçáo nas tramas provocativas da paisagem dogmática do pensamento}

O pensamento no ocidente moderno sempre esteve engendrado nas tramas provocativas de uma geografia ortodoxa, moral e julgadora, que labuta no apagamento das multiplicidades e da exceção (DELEUZE, 2006). Um pensamento compromissado com a representação, promovendo a identidade, a semelhança e a repetição do mesmo, e nele se reforça o exercício de mortificação do corpo e da linguagem, negando, sobretudo, a diferença.

Na obra "Diferença e Repetição" (2006), Deleuze, influenciado por Espinosa e Nietzsche, denuncia essa imagem dogmática do pensamento, fundamentada em uma filosofia da tradição, que não cessa de subjugar a diferença ao identitário. $\mathrm{Na}$ obra "Para além do bem e do Mal" (1992) Nietzsche preconiza que o homem tem sido edificado pela razão do julgamento, e persuadido pelo pensamento moralizante, direcionando-o a uma forma de pensar, de ver, de agir, de aprender.

A imagem dogmática do pensamento, da moral e do juízo atravessa a educação. Os tratados pedagógicos estão recheados por essa doutrina do pensamento representacional. Enveredados por essa axiomática "formar" pressupõe uma busca no interior do sujeito por um "Ser" modelado, aprimorado e aperfeiçoado, desde que trilhado um caminho correto "que leva à correção e à negação de um homem "falhado" e "incompleto", no qual o verdadeiro e a unidade devem ser caracterizados pela modelagem da imagem da "boa forma", da boa conduta e do bom método" (BRITO, 2015, p. 103), há todo um esforço para modelar o "bem formado", qualquer possibilidade de fissura, de estranhamento dessa imagem deve ser desprezada.

A formação de professores tem sido lançada ao deserto do pensamento representacional que visa às generalizações, negando tudo aquilo que escapa dessa ordem, a diferença e as singularidades. Existe uma rigidez para conceber uma formação que escape aos modelos, às verdades, ao universal. Uma formação por travessias, passagens, movimentos em aliança com a singularidade. Gallo (2003)

6 O texto é um esforço cartográfico maquinado no transcorrer da disciplina de Epistemologia das Ciências ministrada no curso de Licenciatura Integrada em Educação em Ciências, Matemática e Linguagens da Universidade Federal do Pará. O recorte foi nas aulas produzidas em conjunto pelos professores em formação inicial junto com a professora e um aluno da pós-graduação em seu exercício de estágio de docência, requisito exigido pelo programa e pela capes. 
menciona todo um projeto voltado para uma pedagogia moderna constituída nos moldes da massificação e da universalização estabelecidas como ideias, forças, estratégias pedagógicas traçadas que tenham como objetivo educar a todos, estabelecer e manter um padrão, desconsiderando a produção de singularidades maquinadas nos espaços formativos, saltando os processos educativos.

$\mathrm{Na}$ esteira da formação de professores tal pensamento é potencializado pelas práticas pedagógicas, que partem do princípio de que o sujeito comporta uma essência, uma identidade, logo, existe um modo de aprender universal, comum a todos. Portanto, uma formação de professores em consonância com a modelagem do sujeito, com a aplicabilidade, a qual busca no "método seguro", uma "forma" para ensinar algo (RAMOS; BRITO, 2014).

É preciso pontuar que enfrentamentos vêm sendo travados no interior dos espaços formativos, criando lugares-outros, por onde vazam processos criativos, e neste entre-lugar, nas fronteiras borradas, no horizonte fendido que a formação de professores pode ser pensada por travessias.

Nesse entre-lugar que podemos chamar de sala de aula é possível a emergência do heterogêneo, do dissenso, do trabalho com as minoridades, com gestos singulares que escapem a universalidade como se fossem uma espécie de resistência ou mesmo um grito: "ainda são possíveis outras formações, outros modos de existências"; esse grito exige também guerrilha, luta com o que quer perseverar do mesmo.

Um trabalho que remete cavar uma toca diária com os padrões curriculares, com as didáticas modelares e com as metodologias pedagógicas unificadas. Essa toca nada mais é do que abrir fenda numa "crença" em que a formação de professores possa resistir à maquinaria estatal para quem sabe brotar a diferença.

\section{Travessia II: Formaçáo de professores para as singularidades}

Uma formação de professores deslocada da imagem dogmática do pensamento remete a uma aventura, um desafio, uma aliança com a diferença, pois "somente um compromisso com o ato de singularização pode forjar fluxos, misturas, que escavam, rasgam e provam desejos, produções, fazendo, então, passagens, agenciamentos, territorialidade e desterritorialidades" (BRITO, 2015, p. 107), mas alerta-se que tal formação em nenhum momento pretende uma modelagem, muito mais um exercício experimental na labuta diária do ofício professoral, uma labuta inclusive nos próprios cursos de formação de professores, na tarefa política que cada docente assume nesse enfrentamento com a formação inicial ainda tão desejosa de modelos e boas práticas.

Pensar uma formação de professores que percorra as linhas da singularidade não pressupõe um caminho reto ou uma forma, mas, estranhar toda forma de boa vontade, o método salvacionista, o senso comum, isso nos parece ser uma possibilidade de entrada, pois esse exercício de estranhar o que está posto produz, 
ao menos, abalos na paisagem dogmática para pensar uma imagem-outra da formação de professores (RAMOS; BRITO, 2014).

Gilles Deleuze ${ }^{7}$, um pensador que busca nos intercessores uma potência para criar seus conceitos, irá beber dos escritos nietzschianos para produzir uma "teoria das singularidades", forjada em toda a sua produção filosófica. Para esse autor a singularidade não está ligada a um eu, a um centro detentor do conhecimento, a um sujeito unificado. Pode-se dizer que esse conceito se aproxima daquilo que Nietzsche chama de multiplicidades de forças.

A singularidade atravessada por n-s forças. Não se é um eu centrado, solista, harmonioso, fixo que pode ser formado em uma fixidade identitária. Singularidade é tudo que agencia um acontecimento, muito mais próximo do que Deleuze chamaria de heiccidade, eis aqui, agora, isso que se atualizam em n-s dobras e redobras, em linhas e entre linhas que se conectam por todos os lados, pois não se é.

As dobras podem potencializar sentidos sobre esse conceito tão difícil e complexo na filosofia deleuziana que nos permitem deslocar essa paisagem conceitual para a ideia de formação. A formação, assim percorreria muito mais as linhas da (de)formação em um sentido aberto ligado às passagens, às travessias, estranhamentos, acontecimentos, nunca um solo permanente, mas puro exercício de experimentação, envolvida por forças, encontros, desencontros, intensidades, composições, decomposições... É toda uma questão de como um corpo entra em ligação com outros corpos, a formação não é, mas sugerimos, em vez de um verbo, a conjunção "e".

Entretanto, é preciso prudência quando se fala em uma formação pelos processos singulares, quando vistas como planejamento coletivo ou um modelo a ser seguido. Gallo (2016, p. 4, grifo nosso) alerta que não é "possível planejar ações formativas professorais que eduquem pelas vias da singularidade”, pois poderíamos acabar retornando as bases fundamentais da representação, tornando o "formar para e pela singularidade" um modelo, mais um entre tantos tratados pedagógicos que modelam o professor, resultando no apagamento da diferença "o paradigma da singularidade na educação seria a imposição de uma nova regra, de um novo ponto médio, para o qual tudo e todos deveriam convergir. De modo que a exceção viraria a "nova regra" e, uma vez mais, perderíamos as diferenças" (GALLO, 2016, p. 3).

Entendemos que é problemático pensar em práticas professorais voltadas a modelagem de professores para a singularidade. Arriscamos a pensar um espaço formativo como um mapa de intensidades, no qual podemos exercitar, na força do "estar junto", no máximo de alteridade, o estimulo ao olhar sensível do professor em formação inicial, para aquilo que escapa da regra, que transborda e ascende a

7 É importante ter em mente que este autor não produz em seus tratados filosóficos uma filosofia da educação, nem faz qualquer incursão à educação, pois a escola é um lugar institucionalizado, por isso buscamos na obra desse autor inspiração para pensar a educação, sem demarcar interpretações desnecessárias. 
diferença. Para isso, seria interessante que o professor pudesse estar destituído de uma imagem moralizante, abrindo mão de uma verdade formativa, atuando assim como um vetor, não mais de representação para possibilitar a multiplicidade.

A sala de aula, formalizada por uma instituição de ensino é um território instituído para operar segundo os desejos do Estado, possibilitando ou não a prática de certas ações, estando o professor impelido neste processo. Diante disso a tarefa de se aventurar pela formação de professores; parece-nos que seria aceitar a de sala de aula como desafio, assim territorializar-se nesse espaço, deixar-se capturar pelas forças da maquinaria formativa é uma provocação diária que se faz latente na vida do professor. Entretanto, é esse o espaço que é "dado" ao professor, é nele que o movimento é possível, que a vida acontece e se tecem nas mais impensáveis teias. Desafiar o formativo nesse espaço é não se deixar minguar pelas forças negativas.

Assim, o professor sensível aos acontecimentos destitui a paisagem ortodoxa que recobre a imagem do bom mestre formador, buscando na força do coletivo, na alteridade, no estar juntos, sem hierarquia, professorandos e professor, detentores do seu processo formativo, educando a si mesmo na convivência, nesse trabalho que não é nada fácil, nem confortável... Abandonar o ideal da "boa formação" nos parece uma possibilidade para escavar outros possíveis, pois não existe "fundo" da formação, e não estaremos formando para uma completude, é bom que assim seja, pois há sempre algo novo aprender com o outro, com conjunto, com as diferenças.

\section{Travessia III: por uma cartografia das singularidades}

Pode-se perguntar: o que é uma cartografia? Com Deleuze (2006) sabemos que ela não é um método, preferimos pensar como um plano de composição, com suas múltiplas aberturas, tocas, zonas, entradas, linhas de desejo e saída, entramos com prudência por uma dessas fissuras, sem objetivo a priori, ou um objeto a ser decifrado... Não há um caminho a seguir, mas zonas de experimentação povoadas pelas singularidades e pelo o heterogêneo. Encontramos na alteridade, no estar junto, um fio vermelho condutor, um olhar sensível ao que escapam dos processos formativos, as diferenças, pois uma cartografia remete ao ai, ao que se dar no e com o acontecimento. Não é o que passa, mas o que passa em mim, o que atravessa em mim, o que compõe e decompõe o corpo, mas não um corpo qualquer, o corpo que é afetado por aquilo que nela passa e vive.

Esta cartografia foi experimentada em uma sala de aula de um curso de Formação de Professores para séries iniciais, Licenciatura Integrada em Educação em Ciências, Matemáticas e Linguagens.

A professora, responsável pelo eixo "Epistemologia das Ciências", apresentou o programa para turma, solicitando aos professorandos que tecessem considerações sobre seus anseios formativos que pudessem transversalisar com o eixo temático. Ouvidos atentos.. Um a um comesam a expor suas dificuldades... Professora anota. Ao final, uma proposta: aulas abertas, criadas na coletividade, professorandos e professora, sem hierarquias, ensaiar juntos aulas, não seria fácil experimentar um 
eixo temático para a formação de professores em educação em ciências saindo dos padrões ementários que regem a condução de um processo disciplinar.

Foi um mergulho em um rio sem as técnicas da natação, no meio de tudo isso que parecia muito mais um caos instalado eu seguia a intuição no aprendizado que exige encontrar aquilo que pode compor um corpo entre outros corpos e se permitir a aventura de entrar em um rio nadando precariamente, lá fui eu nesse barco dirigido por tantas mãos na tentativa de fazer bloco sensíveis aparecerem naqueles que estavam ansiosos por serem formados em professores Esses blocos passaram no meu próprio corpo. Não há receitas para formar ninguém, nem mesmo o professor...

Olhares atentos, o estranhamento à espreita, algumas perguntas, breve esboço de sorrisos, animação... Que traçados são desenhados pelas singularidades no interior dessa sala de aula? Fiquei a perguntar, como sentir o singular nas atividades professorais sob a exigência da universalização? Quais sentidos são escavados pelo singular? Que experiências sensíveis fora, produzidas nesse curso de formação? Que cartografias são maquinadas pelas singularidades nesse espaço?

\section{Aula-Ensaio $\beta$ : Ler, Escrever e fotografar a cidade Belém-PA}

Entre tantos encontros, uma aula é aberta em processo experimental. Quem é o professor? Quem são os professorandos? Quem aprende? Quem ensina? Não sabemos... Algumas questões são lançadas:

Uma aula...

O que é a cidade? Como nos conectamos com a cidade? A cidade nos pertence? Podemos escrever a cidade? Seríamos um estrangeiro a vagar pela cidade? Ficamos ali em grupo maquinando essas perguntas... No interstício de uma reflexão e outra, um exercício é proposto escrever e fotografar a cidade de BelémPA, embebidos de um olhar-outro, não mais para os pontos turísticos, históricos que enxertam os livros de história e geografia, mas um olhar para o incerto, para as encantarias, aquilo que nos afeta nos arrastando para uma cidade-outra. Fotografia e escrita são convocadas ao processo.

Desafio lançado! Professorandos e professora retornam ao espaço da sala de aula, compartilham a experiência, expõem suas imagens, lêem em vOz alta aquela narrativa, escuta o colega, lêem as narrativas dos outros, imagens são trocadas, gestos são desenhados, Para compor está escrita, trago uma imagem/narrativa de uma professoranda, intitulada $O$ mistério casa da vila jardim. 
Figura I: A casa abandonada da vila

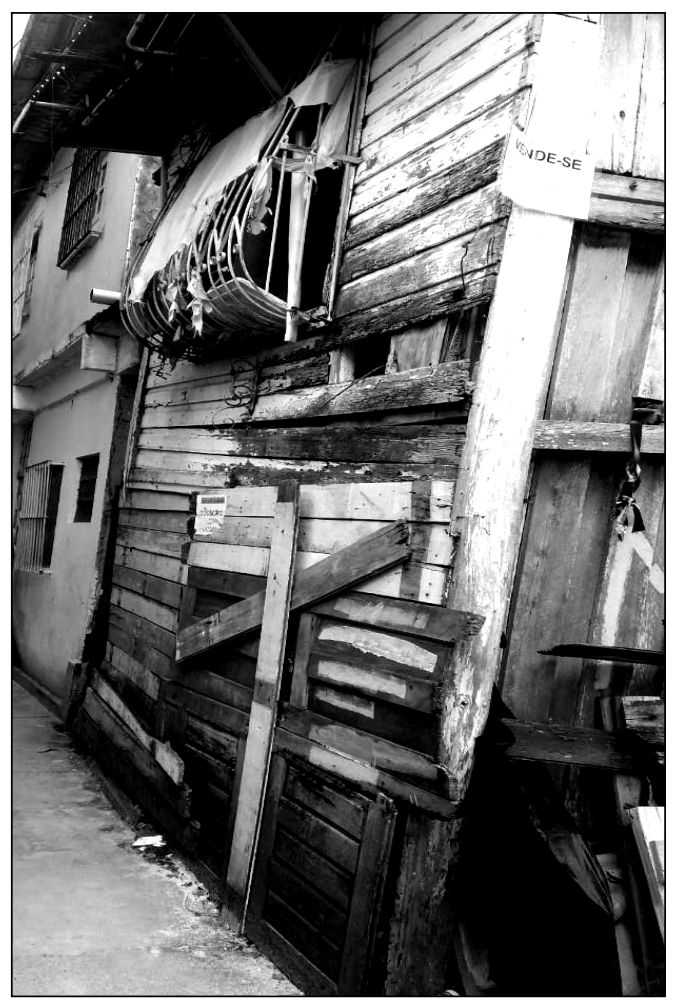

Fonte: Fotografia da aluna Denise Teixeira

Trago para vocês uma imagem de uma casa lá da minha rua. Ela tem uma bistória, contada pelos meus avôs. Conta-se que no surgimento dessa rua existiam apenas três casas afastadas umas das outras, sendo uma da D. Maria, uma da D. Nazaré e última da D. Neide, mais conhecida como "a mulher que virava bicho", um boato maldoso inventado, mas que acabou influenciando na organização das casas, pois ninguém queria construir sua casa ao lado da "mulher que virava bicho", ficando isolada. Mesmo passando tanto tempo, ainda existe um medo da população local de chegar perto da residência, hoje abandonada, apresentando ainda os traços da arquitetura da época, haja vista que ninguém nunca resolveu morar na casa depois que D. Neide morreu. Não sei se é verdade, só sei q eu não passo por lá... (Professoranda)

Entre encantarias e misticismos, olhares atentos vislumbram aquela imagem, ouvidos a espreita, alguns sorrisos ao fundo. Entusiasmo, curiosidade, medo... n' sensações povoam aquele território. Professorandos contam suas próprias histórias, fazem questionamentos, demonstram interesse. Alteridade! Fico atento a cada movimento... Daquela imagem, narrativa, misticismo, percebo que algo entra em operação, variação e disjunção, velocidade e lentidão, jogos de forças e seus problemas, composição de afetos, desejos, arranjos... Produzem uma gagueira na língua, no julgamento moral da boa ou ruim aula. Como narrar à cidade? Ela entra na 
sala de aula? Existe uma cidade universal? Algo de singular atravessava àquela imagem, corpos, escrita, um conhecimento se inscreve.

Não estávamos preocupados com os currículos oficiais e as diretrizes que regimentam o desenvolvimento do tema "cidade" para os anos iniciais, mais que isso, aqueles corpos destituídos do rosto moral do bom professor e bom aluno, estavam produzindo algo, criando e inventando... Uma paisagem para a formação por onde vaza toda a potência do pensamento. Uma prática pedagógica se engendrava, assim como uma formação que não se sabe onde isso pode reverberar, se reverberar. Em tudo parecia que alguma coisa ali acontecia... Em nenhum momento as aulas criadas na sala de aula seriam modelos para servirem aos professorandos... sobretudo, aquilo tudo permeavam suas próprias provocações...seus anseios, suas curiosidades, suas emergências, suas implicações com o mundo, com a vida.

\section{Aula-Ensaio $\varphi$ : Rastros da infância}

Não há infância que as pedagogias não atinjam...

A infância toma conta da sala de aula. Registrar, com auxilio do celular, crianças, vozes, passeios, brincadeiras, desenhos, fotos, anotações de frases... Crianças da família, do trabalho, do bairro... Deseja-se perceber como essa infância aparece nesses pequenos corpos viventes. Somos compelidos por essa atividade... Uma aula é iniciada. Apresentamos uns aos outros...

A criança quer se comunicar, mas não estamos sensiveis a essa linguagem outra que não é da fala oral, essa lingua da criança passa por todo o corpo. No estágio percebo que a criança corre, risca as paredes, brinca, sorrir, chora... Uma vida pulsante, diz uma professoranda. (Professorando).

A criança não tem segredo... A criança não conbece a lei, a regra e por isso inventa um modo de existir... A criança é criativa, um lápis e papel se tornam uma porta para um mundo que é só deles, deviamos ser mais como crianças. (Professorando).

E nossa infância de professor? Olhamos a infância da criança, dizemos como ela é mágica, mas somos capazes de olhar para a nossa? Que ruídos ressoam desse lugar?... Naquele momento, aqueles corpos decidem fissurar o espaço formal da sala de aula... Arrastam as cadeiras para o canto, sentam no chão, tiram os sapatos, um grande cartaz é aberto no chão... Sem hierarquias começam a desenhar as travessias da sua infância... Resolvo me retirar, olhar de longe... Fotografo, anoto e desenho... 
Figura II: Mapa da Infância

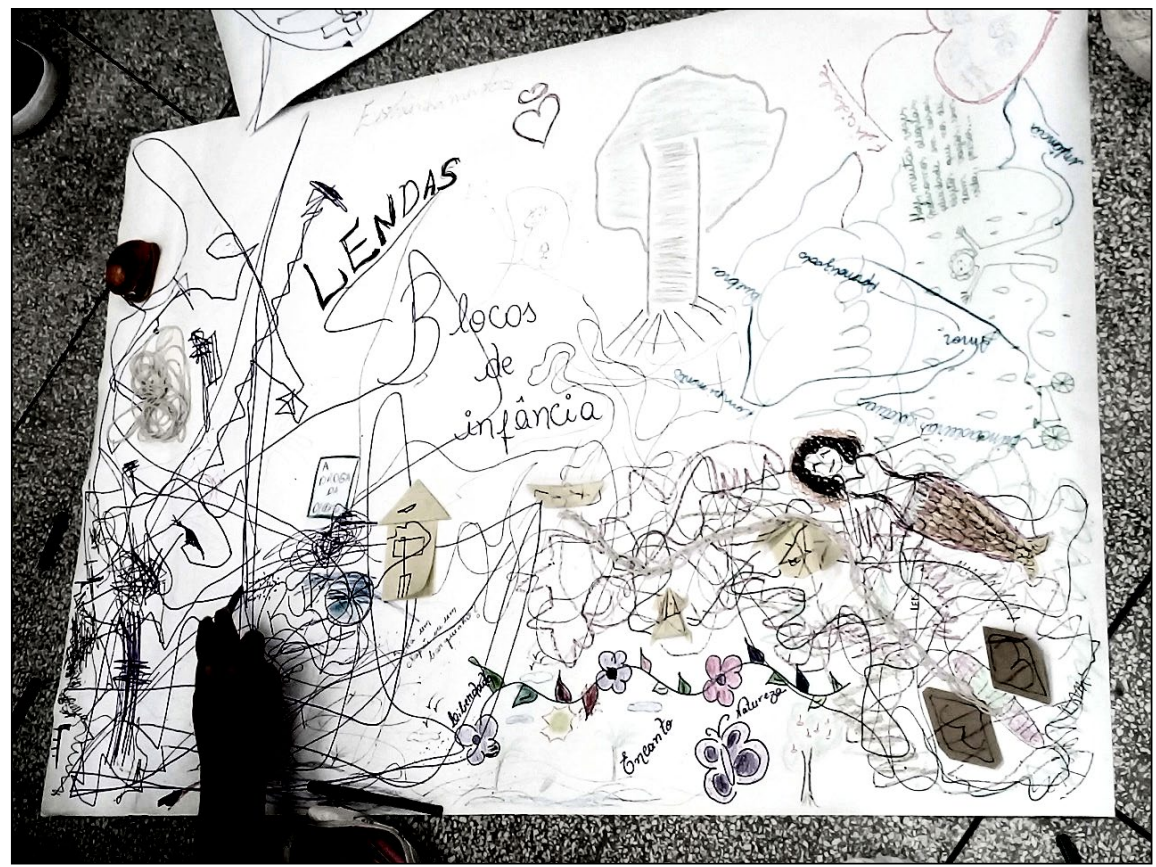

Fonte: Fotografia do autor.

Juntas, aquelas infâncias formam um mapa, sem caminhos para percorrer destinos, forma coordenadas geográficas, aquele mapa não queria ser decifrado, mas sentido.

Minha infância tem um rio, tem brincadeiras, tem boto, tem Iara, tem muito açaí, a gente só brincava o dia todo, no fim da noite contava história, tinha escola também, quando a maré baixava papai colocava todo mundo dentro da rabeta, todo dia uma aventura diferente... Às vezes sinto até saudade, mas agora tá bem melhor pra estudar... (Professorando).

Falar da nossa infância é doloroso, dá um nó na garganta, um gosto amargo, uma saudade, uma nostalgia. Na minha infância tem a casa da minha avó, nas férias juntava todos os primos, brecávamos o dia todo, juntava a turma da rua de cima, a gente era feliz, queria uma infância assim para minha filha. (Professorando).

Silêncio toma conta do lugar, professoranda chora, lembra da família, dos sacrifícios de morar longe em prol da formação, sente saudades, colegas observam, tentam consolar, narram suas próprias experiências, falam das dificuldades da formação inicial, dos desafios de educar em comunidades ribeirinhas, lançam alguns problemas, tentam desenhar uma solução. $\mathrm{O}$ adiantar da hora nos convida a encerrar o processo, mas na certeza que aquela aula não acabou ali, algo de singular reverbera e lateja naqueles corpos. A professora volta a perguntar: que infância pode habitar na vida de um professor e o que isso traduz de potências para uma prática formativa? 


\section{Aula-Ensaio ๗: Educação infantil e seus ruídos: os sons que ecoam da sala de aula}

A escola não suporta corpos indisciplinados ou mesmos barulhentos... O que pode o professor com os ruídos da infância? As formações de professores estão atentas a eles?...

A escola tem barulho Quem produz? De onde vem? Para onde vai? O que querem dizer? Prostramo-nos a uma escuta sensível? Quais vozes são aceitas na sala de aula? Quais ruídos são desejados, incentivados? Essas questões vão adentrando a sala de aula, um interesse pela infância aparece nesse curso de formação de professores em Educação em Ciências...., os ruídos que faz ressoar, uma preocupação com o "formar a si mesmo" para as singularidades da infância, um olhar para aqueles gestos, vozes, movimentos que são banalizados no espaço formativo... Se a educação ao percorrer as linhas do pensamento dogmático busca ouvir das crianças as respostas corretas aos exercícios, a disciplina e a ordem, aqueles professorandos não parecem interessados na disciplina dos corpos, ao contrário, demonstram um interesse por aquilo que salta a normalidade... Gritos, choros, cânticos, correria, falas... Esses gestos podem oferecer dignidade ao pensamento, potencializando entradas para o aprender... Professorandos levam para a sala de aula áudios, gravados durante o estágio de docência. Ouvimos com atenção, olhos começam a brilhar...

Nossa já fiz vários estágios, mas nunca parei pra ouvir com atenção... O que será que elas querem dizer?... (Professorando).

Acho que esse som acaba sendo naturalizado pelos professores, não ouvem, não escutam, não enxergam, mas não creio que seja culpa deles não, somos direcionados a olhar o coletivo, precisamos de números, alcançar os indices avaliativos, o sistema é perverso, não dá espaço para criação... (Professorando).

Percebo uma angústia nos professorandos, os demais compartilham da mesma visão, uns mais esperançosos, outros mais pessimistas. Diante daquele posicionamento, uma questão é lançada: como formar um professor para a precariedade da escola? Entendemos que jamais estaremos formados, acreditamos mais em um devir formação de professores, nunca estaremos completos, há sempre algo a aprender, há sempre um problema novo, um desafio ainda por vir. O som e os ruídos que ecoam da escola podem até ser marginalizados, vulgarizados, mas ali, naquele lugar, entraram em composição, forças turbilhonares capazes de emitir signos que violentaram o pensamento.

\section{Travessia IV: Uma toca, uma saída, uma máquina e guerra}

A formação de professores é ainda um território fechado, com suas diretrizes, parâmetros e currículos moldam um sujeito universal, uma identidade desejada. Contudo, Professorando e professor não são estruturas acabadas, comportam em suas subjetividades uma multidão, cada um com sua singularidade produzida pela ordem dos encontros, por aquilo que se deixou ser afetado. Em uma sala de aula de 
um curso de formação de professores as singularidades escapam desse sistema de massificação universal, produzem fissuras, frestas. Uma formação de professores que percorre as linhas da diferença, sem fazer dela um modelo, encontra nessas aberturas toda uma potência para fazer do pensamento um vôo criativo, um pensamento que não busca o idêntico, mas, sobretudo, a invenção.

Entretanto, é preciso ter em mente que uma sala de aula é um espaço institucionalizado, aproxima-se daquilo que Deleuze e Guattari denominam de espaço estriado, ele impede e dificulta o movimento dos fluxos, produzem repetição. Por outro lado, existe também um espaço liso, onde os fluxos fluem livremente, produzem a diferença. Pensar uma formação de professores comprometida com a diferença é abdicar de todo e qualquer controle, pois a diferença não pode ser domada, controlada, sob pena de retornar ao mesmo.

Gallo (2003) prefere pensar que é possível criar uma máquina de guerra na sala de aula, capaz de resistir à máquina do estado, traçando linhas de fuga em meio às misérias da educação, dando dignidade as singularidades que povoam o interior do espaço institucionalizado, produzindo formações outras, para além daquilo que foi ensinado, formatando, mas um vetor de diferenciação, o ver de outro jeito, com o olhar curioso.

Deleuze (2006) nos convida a estranhar os modelos totalitários que tomaram conta da sociedade, inventar outros modos de existência. Deslocamos o seu caloroso convite para o campo da formação de professores para criarmos outros modos de ensinar e aprender através de uma educação sensível as singularidades, fazer delas uma potência de criação, fugido das armadilhas do pensamento dogmático. Não se trata de uma tarefa fácil, uma formação de professores nessa perspectiva é uma aventura, acima de tudo experimental e não modelar.

\section{REFERÊNCIAS}

BRITO, M. R. Entre as linhas da educação e da diferença. São Paulo: Editora Livraria da Física, 2015.

DELEUZE, G. Diferença e repetição. 2. ed. Tradução de Roberto Machado e Luiz Orlandi. Rio de Janeiro: Graal, 2006.

GALLO, S. Deleuze e a Educação. Autêntica, 2003.

. Possibilidades e linhas de fuga: a invenção e escolas outras no dia a dia. Revista

Eventos Pedagógicos. v. 1, n. 1, p. 1-10. 2016.

GIL-PÉREZ, D; CARVALHO, A. M. P. Formação de professores de ciências: tendências e inovações. São Paulo: Companhia das Letras, 1993.

GONÇALVES, T. O.; GONÇALVES, T. V. O. Reflexões sobre uma prática docente situada: buscando novas perspectivas para a formação de professores. Cartografias do trabalho docente: professor (a)-pesquisador (a). Campinas-SP: ALB, 1998. 
NIETZSCHE, F. Para além do bem e do mal. Tradução e notas de Paulo César de Souza. São Paulo: Companhia das Letras, 1992.

NÓVOA, A. Formação de professores e trabalho pedagógico. Educa, 2002.

RAMOS, M. N.; BRITO, M. R. C. Do pensamento dogmático ao pensamento-problema: por uma aprendizagem-acontecimento. Comunicações, v. 21, n. 2, p. 183-198. 2014.

SCHÖN, D. A. Formar professores como profissionais reflexivos. In: NÓVOA, A. (Coord.). Os professores e a sua formação. Tradução Graça Cunha, Cândida Hespanha, Conceição Afonso e José António Sousa Tavares. Lisboa: Publicações Dom Quixote, 1992. p. 77-91.

ZEICHNER, Kenneth M. A formação reflexiva de professores: idéias e práticas. São Paulo: Educa, 1993. 